\title{
Viscosity of Associated Mixtures Approximated by the Grunberg-Nissan Model
}

\author{
W. Marczak • N. Adamczyk • M. Łężniak
}

Received: 28 March 2011 / Accepted: 29 September 2011 / Published online: 15 October 2011

C The Author(s) 2011. This article is published with open access at Springerlink.com

\begin{abstract}
Previous experiments demonstrated that microheterogeneities occur in liquid systems (2-methylpyridine or 2,6-dimethylpyridine) + water. They are most probably due to the association of the hydrates through hydrogen bonds between water molecules. Substitution of methanol for water causes that the mixtures become homogenous. The results of viscometric studies reported in this study confirmed that the molecular clusters in aqueous solutions are much larger than the complexes occurring in the methanolic systems. Taking into consideration "kinetic entities" rather than monomeric molecules, the dependence of viscosity on concentration and temperature have been satisfactorily approximated by the Grunberg-Nissan relation with two adjustable coefficients. The kinetic entities were trimers of water, dimers of methanol, and monomeric amines. The same approach proved to be valid for the activation energy of viscous flow as well.
\end{abstract}

Keywords Aqueous solutions - Grunberg-Nissan model · Hydrogen bond . Methanol $\cdot$ Pyridines

\section{Introduction}

Small-angle neutron scattering has shown that aggregates of amine-water complexes arise in aqueous solutions of pyridine and its methyl derivatives [1]. In methanolic mixtures, the complexation through hydrogen bonds $\mathrm{O}-\mathrm{H} \cdots \mathrm{N}$ occurs as well, but the amine-methanol complexes do not associate, because of the lack of proton-donating functional groups. Only one proton per molecule capable of participating in the hydrogen bonds causes that methanol molecules in the liquid phase form linear chains with

W. Marczak $(\varangle) \cdot$ N. Adamczyk · M. Łężniak

Institute of Chemistry, University of Silesia, Szkolna 9, 40-006 Katowice, Poland

e-mail:marczak@ich.us.edu.pl 
occasional branches [2] and cyclic structures, as was concluded from DFT calculations [3]. Molecular aggregates in water and aqueous solutions are more complex structures.

The aggregation of aqueous complexes was postulated to explain, e.g., the effect of $\mathrm{H} / \mathrm{D}$ isotopic self-organization in the crystals of 2,6-dimethylpyridine hydrate $\mathrm{C}_{7} \mathrm{H}_{9} \mathrm{~N}$. $\mathrm{H}_{2} \mathrm{O}$ [4]. Thus, the co-operative strengthening of the $\mathrm{O}-\mathrm{H} \cdots \mathrm{O}$ bonds between the molecules neighboring the $\mathrm{O}-\mathrm{H} \cdots \mathrm{N}$ bond is more pronounced in aqueous systems than in methanolic ones. Consequently, although neither water nor methanol are inert solvents for pyridine and its derivatives, the effects of mixing may be different. For example, the aggregation is manifested in the ultrasonic absorption and in the excess expansibility [1], while the first enthalpies of solution of water and methanol in pyridines are approximately independent of the solute [5]. That is because the latter function is sensitive mainly to the $\mathrm{O}-\mathrm{H} \cdots \mathrm{N}$ bond strength. The energies of hydrogen bonds between the molecules of pyridine and water or pyridine and methanol are approximately equal one to another: $18.5 \mathrm{~kJ} \cdot \mathrm{mol}^{-1}$ and $18.9 \mathrm{~kJ} \cdot \mathrm{mol}^{-1}$ calculated by the DFT method while $(17.2 \pm 0.5) \mathrm{kJ} \cdot \mathrm{mol}^{-1}$ and $(18.3 \pm 0.2) \mathrm{kJ} \cdot \mathrm{mol}^{-1}$ are estimated from NMR data [6].

In this study, the viscosities and activation energies of viscous flow are reported for four binary systems: water +2 -methylpyridine, water $+2,6$-dimethylpyridine, methanol +2 -methylpyridine, and methanol +2 ,6-dimethylpyridine. It has been shown that the viscosity of aqueous mixtures differs significantly from that of methanolic ones because of the molecular clusters formed by hydrates. Moreover, the modified Grunberg-Nissan correlation was applied to all the mixtures studied. Although not recommended for associated solutions [7], the correlation turned out to be at least satisfactory when concentrations were defined in terms of "kinetic entities" rather than as the mole fractions of monomeric forms.

\section{Experimental}

\subsection{Chemicals}

2-methylpyridine (Merck, min. $98 \%$ ) and 2,6-dimethylpyridine (Sigma-Aldrich, min. $98 \%$ ) were distilled using a rectifying column filled with glass rings. During the distillation, vapors remained in contact with a drying agent containing ca. $60 \%$ of $\mathrm{Na}_{2} \mathrm{O}$. Methanol (POCh, min. 99.9\%) was used as supplied by the manufacturer. The chemicals were stored over molecular sieves $4 \AA$ A. A comparison of experimental densities and viscosities of pure liquids with literature data is given in Table 1. Water was double-distilled and had an electrolytic conductivity of $1.5 \mu \mathrm{S} \cdot \mathrm{cm}^{-1}$.

Binary mixtures were prepared by a weighing method, using an analytical balance Ohaus AS-200. The uncertainty in mole fractions was $5 \times 10^{-5}$ in the most unfavorable case.

\subsection{Apparatus}

Kinematic viscosities $v$ were measured with Ubbelohde viscometers (capillary 0a, diameter ca. $0.5 \mathrm{~mm}$ ) immersed in a thermostated water bath. The flow time was 
Table 1 Densities and viscosities of pure chemicals

\begin{tabular}{llllllll}
\hline Chemical & \multirow{2}{*}{$T(\mathrm{~K})$} & \multicolumn{2}{l}{$\rho\left(\mathrm{kg} \cdot \mathrm{m}^{-3}\right)$} & \multirow{2}{*}{$T(\mathrm{~K})$} & \multicolumn{2}{l}{$\eta(\mathrm{mPa} \cdot \mathrm{s})$} & \\
\cline { 3 - 4 } & & & & & This study & Literature & Literature \\
\hline Methanol & 293.15 & 791.28 & $791.4^{\mathrm{a}}$ & 298.15 & 0.549 & $0.544^{\mathrm{a}}$ \\
2-Methylpyridine & 293.15 & 943.34 & $944.2^{\mathrm{b}}, 944.3^{\mathrm{a}}$ & 293.15 & 0.804 & $0.8102^{\mathrm{c}}$ \\
2,6-Dimethylpyridine & 293.15 & 922.44 & $922.6^{\mathrm{a}}$ & 298 & 0.809 & $0.795^{\mathrm{d}}$ \\
\hline
\end{tabular}

${ }^{a}$ Ref. [8]

b Ref. [9]

c Ref. [10]

d Ref. [11]

between $200 \mathrm{~s}$ and $1600 \mathrm{~s}$, measured with a resolution of $0.1 \mathrm{~s}$. Each measurement was repeated at least three times for each temperature. To improve the accuracy, Hagenbach-Couette corrections were introduced to the measured times [12]. The viscometers were calibrated at temperatures from $293 \mathrm{~K}$ to $318 \mathrm{~K}$ in $5 \mathrm{~K}$ intervals using water as a standard liquid. Its viscosity was taken from critical tables [13].

The temperature of the bath was measured by a platinum resistance thermometer DRT-10 with a resolution of $0.01 \mathrm{~K}$ and an uncertainty of ca. $0.1 \mathrm{~K}$. The thermometer was calibrated against a reference one, Ertco-Hart 850 equipped with a Pt100 probe. The Ertco setup was calibrated by the manufacturer using standards traceable to NIST.

Densities $\rho$ were measured using a vibrating-tube densimeter Anton Paar DMA5000 with a resolution of $1 \times 10^{-3} \mathrm{~kg} \cdot \mathrm{m}^{-3}$ and an uncertainty of $5 \times 10^{-2} \mathrm{~kg} \cdot \mathrm{m}^{-3}$ in the same temperature range as the viscosities. Parabolic functions fitted by the least-squares method were used to approximate the $\rho(T)$ relationships with residual deviations within the measurement uncertainty. Using these functions, densities could be calculated for temperatures matching those for which the kinematic viscosities were determined. Thus, the dynamic viscosities $\eta$ were calculated according to the formula:

$$
\eta=v / \rho \text {. }
$$

The uncertainty of $\eta$ results almost entirely from that of $v$. It was estimated as $0.5 \%$ of the measured viscosity.

\section{Results}

Dynamic viscosities of the systems methanol + 2-methylpyridine, methanol $+2,6$ dimethylpyridine, and water $+2,6$-dimethylpyridine obtained experimentally are reported in Table 2. The lack of data for the latter system at higher temperatures results from the miscibility gap above $307 \mathrm{~K}$ at mole fractions of the amine $x_{2}$ range from 0.007 to 0.44 [14]. The results for the mixtures of 2,6-dimethylpyridine with water are close to the viscosities reported by Stein et al. [15].

In the classical theories of Andrade and Eyring, the viscous flow of liquids is a thermally activated process with the activation energy related to the intermolecular 
Table 2 Experimental values of the dynamic viscosities

\begin{tabular}{|c|c|c|c|c|c|c|c|c|}
\hline \multicolumn{3}{|c|}{$\begin{array}{l}\text { Water }(1)+ \\
\text { 2.6-Dimethylpyridine (2) }\end{array}$} & \multicolumn{3}{|c|}{$\begin{array}{l}\text { Methanol }(1)+ \\
\text { 2.6-Dimethylpyridine (2) }\end{array}$} & \multicolumn{3}{|c|}{$\begin{array}{l}\text { Methanol (1) + } \\
\text { 2-Methylpyridine (2) }\end{array}$} \\
\hline$x_{2}$ & $T(\mathrm{~K})$ & $\eta(\mathrm{mPa} \cdot \mathrm{s})$ & $x_{2}$ & $T(\mathrm{~K})$ & $\eta(\mathrm{mPa} \cdot \mathrm{s})$ & $x_{2}$ & $T(\mathrm{~K})$ & $\eta(\mathrm{mPa} \cdot \mathrm{s})$ \\
\hline \multirow[t]{3}{*}{0.0297} & 292.65 & 1.806 & 0 & 293.31 & 0.589 & & & \\
\hline & 298.15 & 1.553 & & 298.22 & 0.548 & & & \\
\hline & 302.02 & 1.415 & & 303.21 & 0.511 & & & \\
\hline \multirow[t]{3}{*}{0.0501} & 292.76 & 2.457 & & 308.56 & 0.476 & & & \\
\hline & 298.21 & 2.095 & & 313.25 & 0.446 & & & \\
\hline & 303.17 & 1.932 & & 318.30 & 0.419 & & & \\
\hline \multirow[t]{3}{*}{0.0602} & 292.71 & 2.784 & 0.1115 & 292.38 & 0.767 & 0.1201 & 292.59 & 0.698 \\
\hline & 298.19 & 2.361 & & 298.01 & 0.705 & & 298.25 & 0.641 \\
\hline & 303.05 & 2.172 & & 303.08 & 0.655 & & 303.16 & 0.600 \\
\hline \multirow[t]{3}{*}{0.1001} & 292.73 & 3.838 & & 308.08 & 0.613 & & 308.17 & 0.562 \\
\hline & 298.20 & 3.140 & & 313.15 & 0.572 & & 313.22 & 0.522 \\
\hline & 303.08 & 2.712 & & 318.22 & 0.535 & & 318.26 & 0.490 \\
\hline \multirow[t]{3}{*}{0.2004} & 292.73 & 5.523 & 0.2399 & 292.93 & 0.895 & 0.2351 & 292.54 & 0.782 \\
\hline & 298.23 & 4.298 & & 298.24 & 0.823 & & 303.15 & 0.671 \\
\hline & 303.02 & 3.540 & & 303.21 & 0.763 & & 308.38 & 0.625 \\
\hline \multirow[t]{3}{*}{0.3006} & 292.69 & 5.534 & & 308.25 & 0.710 & & 313.21 & 0.587 \\
\hline & 298.12 & 4.353 & & 312.95 & 0.662 & & 318.25 & 0.550 \\
\hline & 303.17 & 3.538 & & 318.32 & 0.617 & 0.4451 & 292.69 & 0.840 \\
\hline \multirow[t]{6}{*}{0.3981} & 292.89 & 4.600 & 0.2763 & 292.86 & 0.930 & & 298.23 & 0.774 \\
\hline & 298.17 & 3.708 & & 298.12 & 0.857 & & 303.25 & 0.722 \\
\hline & 303.19 & 3.072 & & 303.17 & 0.793 & & 308.26 & 0.676 \\
\hline & 308.21 & 2.587 & & 308.19 & 0.739 & & 313.28 & 0.633 \\
\hline & 313.31 & 2.196 & & 313.25 & 0.688 & & 318.36 & 0.594 \\
\hline & 318.34 & 1.902 & & 318.33 & 0.643 & 0.5511 & 292.75 & 0.846 \\
\hline \multirow[t]{6}{*}{0.5008} & 292.75 & 3.445 & 0.4001 & 293.04 & 0.986 & & 298.23 & 0.782 \\
\hline & 298.16 & 2.844 & & 298.18 & 0.912 & & 303.26 & 0.729 \\
\hline & 303.19 & 2.464 & & 303.21 & 0.850 & & 308.25 & 0.682 \\
\hline & 308.18 & 2.071 & & 313.27 & 0.729 & & 313.28 & 0.641 \\
\hline & 313.25 & 1.794 & & 318.33 & 0.682 & & 318.35 & 0.601 \\
\hline & 318.30 & 1.571 & 0.5482 & 292.70 & 0.988 & 0.6483 & 292.56 & 0.850 \\
\hline \multirow[t]{6}{*}{0.6510} & 292.79 & 2.102 & & 298.18 & 0.909 & & 298.28 & 0.784 \\
\hline & 298.20 & 1.812 & & 303.25 & 0.840 & & 303.22 & 0.733 \\
\hline & 303.26 & 1.593 & & 308.24 & 0.782 & & 308.23 & 0.686 \\
\hline & 308.26 & 1.413 & & 318.35 & 0.688 & & 313.27 & 0.645 \\
\hline & 313.32 & 1.262 & 0.7013 & 292.89 & 0.964 & & 318.29 & 0.606 \\
\hline & 318.37 & 1.134 & & 298.29 & 0.891 & 0.8299 & 292.59 & 0.824 \\
\hline \multirow[t]{2}{*}{0.7887} & 292.79 & 1.144 & & 303.24 & 0.828 & & 298.28 & 0.760 \\
\hline & 298.19 & 1.038 & & 308.26 & 0.774 & & 303.22 & 0.714 \\
\hline
\end{tabular}


Table 2 continued

\begin{tabular}{|c|c|c|c|c|c|c|c|c|}
\hline \multicolumn{3}{|c|}{$\begin{array}{l}\text { Water }(1)+ \\
\text { 2.6-Dimethylpyridine (2) }\end{array}$} & \multicolumn{3}{|c|}{$\begin{array}{l}\text { Methanol }(1)+ \\
\text { 2.6-Dimethylpyridine (2) }\end{array}$} & \multicolumn{3}{|c|}{$\begin{array}{l}\text { Methanol }(1)+ \\
\text { 2-Methylpyridine (2) }\end{array}$} \\
\hline$x_{2}$ & $T(\mathrm{~K})$ & $\eta(\mathrm{mPa} \cdot \mathrm{s})$ & $x_{2}$ & $T(\mathrm{~K})$ & $\eta(\mathrm{mPa} \cdot \mathrm{s})$ & $x_{2}$ & $T(\mathrm{~K})$ & $\eta(\mathrm{mPa} \cdot \mathrm{s})$ \\
\hline & 303.23 & 0.955 & & 313.33 & 0.725 & & 308.23 & 0.669 \\
\hline & 308.23 & 0.881 & & 318.38 & 0.680 & & 313.27 & 0.631 \\
\hline & 313.34 & 0.815 & 0.8449 & 292.98 & 0.912 & & 318.29 & 0.592 \\
\hline & 318.36 & 0.758 & & 298.19 & 0.846 & 1 & 292.54 & 0.812 \\
\hline \multirow[t]{6}{*}{1} & 292.65 & 0.872 & & 303.15 & 0.789 & & 298.18 & 0.751 \\
\hline & 298.20 & 0.806 & & 308.18 & 0.737 & & 303.21 & 0.704 \\
\hline & 303.24 & 0.753 & & 313.22 & 0.691 & & 308.23 & 0.663 \\
\hline & 308.26 & 0.708 & & 318.28 & 0.650 & & 313.29 & 0.623 \\
\hline & 313.34 & 0.663 & & & & & 318.33 & 0.588 \\
\hline & 318.39 & 0.627 & & & & & & \\
\hline
\end{tabular}

Fig. 1 Dynamic viscosity of 2,6-dimethylpyridine: experimental results (points) and the fitted Arrhenius-Guzmán model (Eq. 2)

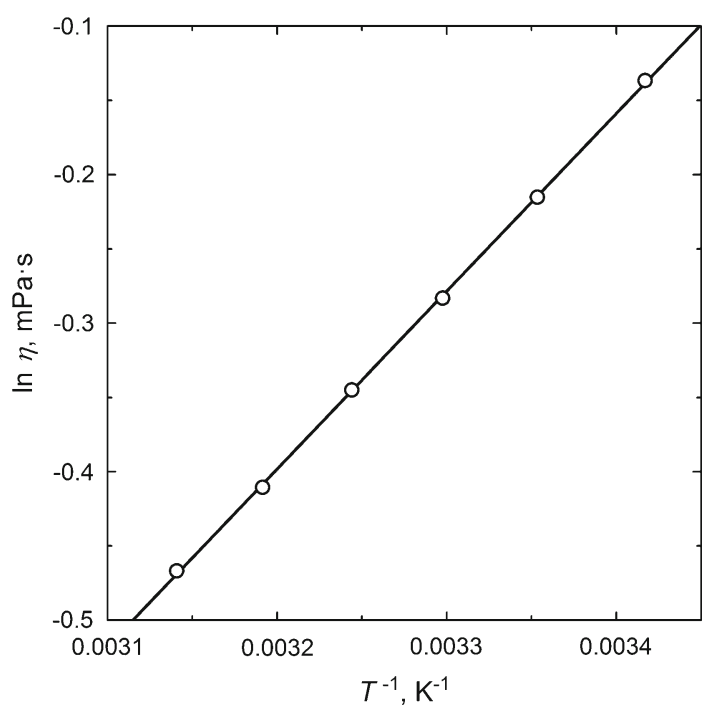

forces $[7,16]$. The Arrhenius-Guzmán equation is the simplest relationship for the dependence of the dynamic viscosity $\eta$ on temperature $T$ for the Newtonian liquid:

$$
\eta=A \exp \frac{E^{\#}}{R T}
$$

where $E^{\#}$ is the activation energy of viscous flow, $A$ is a constant characteristic of the liquid, and $R$ is the universal gas constant. $E^{\#}$ is ca. $8 \mathrm{~kJ} \cdot \mathrm{mol}^{-1}$ to $12 \mathrm{~kJ} \cdot \mathrm{mol}^{-1}$ for typical liquids, while it can be much higher for the associated ones [17]. Thus, the dependences of viscosity on temperature were approximated by Eq. 2. To this 
Table 3 Coefficients of the Arrhenius-Guzmán equation (Eq. 2) and standard deviations of the fit $\delta$

\begin{tabular}{|c|c|c|c|}
\hline$x_{2}$ & $-\ln A(\mathrm{mPa} \cdot \mathrm{s})$ & $E^{\#}\left(\mathrm{~kJ} \cdot \mathrm{mol}^{-1}\right)$ & $\delta$ \\
\hline \multicolumn{4}{|c|}{ Water (1) + 2,6-dimethylpyridine (2) } \\
\hline \multicolumn{2}{|c|}{0.0297} & $19.92^{\mathrm{a}}$ & \\
\hline \multicolumn{2}{|l|}{0.0501} & $21.21^{\mathrm{a}}$ & \\
\hline \multicolumn{2}{|l|}{0.0602} & $21.82^{\mathrm{a}}$ & \\
\hline \multicolumn{2}{|l|}{0.1001} & $26.60^{\mathrm{a}}$ & \\
\hline \multicolumn{2}{|l|}{0.2004} & $33.10^{\mathrm{a}}$ & \\
\hline \multicolumn{2}{|l|}{0.3006} & $32.06^{\mathrm{a}}$ & \\
\hline 0.3981 & $9.544 \pm 0.203$ & $26.92 \pm 0.51$ & 0.0141 \\
\hline 0.5008 & $8.582 \pm 0.145$ & $23.88 \pm 0.37$ & 0.0101 \\
\hline 0.6510 & $6.936 \pm 0.089$ & $18.68 \pm 0.23$ & 0.0062 \\
\hline 0.7887 & $4.993 \pm 0.033$ & $12.47 \pm 0.08$ & 0.0023 \\
\hline 1 & $4.227 \pm 0.029$ & $9.95 \pm 0.07$ & 0.0020 \\
\hline \multicolumn{4}{|c|}{ Methanol (1) + 2,6-dimethylpyridine (2) } \\
\hline \multicolumn{2}{|c|}{$\begin{array}{ll}0 & 4.868 \pm 0.012\end{array}$} & $10.58 \pm 0.03$ & 0.0008 \\
\hline \multicolumn{2}{|r|}{$4.682 \pm 0.018$} & $10.74 \pm 0.05$ & 0.0012 \\
\hline \multicolumn{2}{|r|}{$4.778 \pm 0.017$} & $11.36 \pm 0.04$ & 0.0012 \\
\hline \multicolumn{2}{|r|}{$4.686 \pm 0.015$} & $11.23 \pm 0.04$ & 0.0010 \\
\hline 0.4001 & $4.689 \pm 0.064$ & $11.40 \pm 0.16$ & 0.0044 \\
\hline 0.5482 & $4.516 \pm 0.064$ & $10.95 \pm 0.16$ & 0.0041 \\
\hline $\begin{array}{l}0.7013 \\
0.8449\end{array}$ & $4.401 \pm 0.019$ & $10.62 \pm 0.05$ & 0.0013 \\
\hline 0.8449 & $4.365 \pm 0.021$ & $10.41 \pm 0.05$ & 0.0015 \\
\hline \multicolumn{4}{|c|}{ Methanol (1) + 2-methylpyridine (2) } \\
\hline 0.1201 & $4.754 \pm 0.035$ & $10.69 \pm 0.09$ & 0.0024 \\
\hline \multirow{2}{*}{$\begin{array}{l}0.2351 \\
0.4451\end{array}$} & $4.596 \pm 0.004$ & $10.58 \pm 0.01$ & 0.0003 \\
\hline & $4.465 \pm 0.012$ & $10.44 \pm 0.03$ & 0.0008 \\
\hline 0.5511 & $4.410 \pm 0.015$ & $10.33 \pm 0.04$ & 0.0011 \\
\hline $\begin{array}{l}0.6483 \\
08790\end{array}$ & $4.337 \pm 0.012$ & $10.15 \pm 0.03$ & 0.0008 \\
\hline \multirow{2}{*}{$\begin{array}{l}0.8299 \\
1\end{array}$} & $4.261 \pm 0.027$ & $9.89 \pm 0.07$ & 0.0019 \\
\hline & $4.188 \pm 0.020$ & $9.68 \pm 0.05$ & 0.0014 \\
\hline
\end{tabular}

a Calculated from the viscosities at two temperatures, ca. $293 \mathrm{~K}$ and $298 \mathrm{~K}$

The correlation coefficients $r>0.999$ for all the fits

end, its logarithmic form was fitted to the experimental data for each concentration by the least-squares method. An example illustrating the quality of the fit is plotted in Fig. 1. For aqueous solutions of 2,6-dimethylpyridine at $x_{2} \leq 0.3, E^{\#}$ and $A$ were calculated from the viscosities at two temperatures, ca. $292 \mathrm{~K}$ and $298 \mathrm{~K}$, because the Arrhenius-Guzmán relationship did not approximate appropriately the viscosity nearby the miscibility gap. The results are reported in Table 3 . Viscosities calculated from Eq. 2 are, within the measurement uncertainty limits, equal to the experimental values. The viscosities at $T=293.15 \mathrm{~K}$ and the activation energies of viscous flow for the system water +2 -methylpyridine were taken from papers published previously $[18,19]$. 


\section{Correlations}

There are several correlation equations for liquid mixture viscosity [7]. A simple one is the Grunberg-Nissan model, which for a binary mixture is given by

$$
\ln \eta=x_{1} \ln \eta_{1}+x_{2} \ln \eta_{2}+x_{1} x_{2} G_{12},
$$

where $x$ is the mole fraction, subscripts 1 and 2 denote the mixture components, and $G_{12}$ is an interaction parameter dependent on the components and temperature. However, the Grunberg-Nissan correlation usually gives poor results for polar mixtures, particularly for aqueous systems [7]. To overcome this difficulty, we defined a new scale of mole fractions in terms of "kinetic entities" rather than the analytical ones. Both water and methanol are associated liquids because of hydrogen bonds. The self-association of pyridines is much weaker, as their molecules interact through van der Waals forces. Thus, the viscosity should be related to the concentration of associates of water (or methanol) and of the monomeric form of the amines. The new "kinetic" mole fractions $y$ were defined as follows:

$$
\begin{aligned}
& y_{1}=\left(x_{1} / n\right) /\left(x_{1} / n+x_{2}\right), \\
& y_{2}=x_{2} /\left(x_{1} / n+x_{2}\right),
\end{aligned}
$$

where $n$ is the mean degree of association, $n=3$ for water and $n=2$ for methanol, subscripts 1 and 2 denote water or methanol, and 2-methylpyridine or 2,6-dimethylpyridine, respectively. Taking into consideration the linear dependence of the interaction parameter on temperature, Eq. 3 takes the form,

$$
\Delta \ln \eta \equiv y_{1} \ln \frac{\eta}{\eta_{1}}+y_{2} \ln \frac{\eta}{\eta_{2}}=y_{1} y_{2}\left[G_{12}^{0}-a\left(T-T^{0}\right)\right]
$$

where $\Delta \ln \eta$ is the deviation of the viscosity logarithm from the additivity in the "kinetic" mole fraction scale, $\eta$ is the mixture viscosity, $G_{12}^{0}$ is the Grunberg-Nissan parameter at the reference temperature $T^{0}=293.15 \mathrm{~K}$, and $a$ is constant. Viscosities of pure substances (methanol, 2-methylpyridine, 2,6-dimethylpyridine), i.e., $\eta_{1}$ and $\eta_{2}$, at temperatures equal to those at which the mixture viscosities were measured, were calculated from the Arrhenius-Guzmán equation (Eq. 2) with the coefficients reported in Table 3. The viscosity of water was taken from the critical tables [13]. The fitted coefficients $G_{12}^{0}$ and $a$ are collected in Table 4, while the $\Delta \ln \eta\left(T, y_{2}\right)$ function for the system water $+2,6$-dimethylpyridine is plotted in Fig. 2.

In Fig. 3, the viscosity isotherms are plotted as functions of $x_{2}$. It is evident that the substitution of the "kinetic mole fractions" for the "analytical" ones makes reasonable fitting possible, in spite of strong specific intermolecular interactions. The quality of fit for the other temperatures is similar.

The kinetic approach proved to be valid for the activation energy of viscous flow. The deviation from the additivity term was slightly modified by introducing an empirical exponent $k$ to the $y_{1} y_{2}$ product for the system water $+2,6$-dimethylpyridine: 
Table 4 Coefficients of the Grunberg-Nissan model (Eq. 6), standard deviations of the fit, $\delta$, and correlation coefficients $r$

\begin{tabular}{lllll}
\hline System & $G_{12}^{0}$ & $a\left(\mathrm{~K}^{-1}\right)$ & $\delta$ & $r$ \\
\hline Water + 2,6-dimethylpyridine $^{2}$ & $7.173 \pm 0.140$ & $0.096 \pm 0.012$ & 0.103 & 0.9752 \\
Water + 2-methylpyridine $^{\mathrm{a}}$ & $5.656 \pm 0.071$ & & 0.035 & 0.9968 \\
Methanol + 2,6-dimethylpyridine $_{\text {Methanol + 2-methylpyridine }}^{1.147 \pm 0.011}$ & $0.0052 \pm 0.0007$ & 0.008 & 0.9939 \\
\hline
\end{tabular}

${ }^{\text {a }}$ Viscosities at $T=293.15 \mathrm{~K}[18]$

Fig. 2 Grunberg-Nissan model (Eq. 6) fitted to the experimental deviations of viscosity for the system water + 2,6-dimethylpyridine. The surface at $T>307 \mathrm{~K}$ and $0.02<y_{2}<0.70$ is an extrapolation because of the miscibility gap [14]
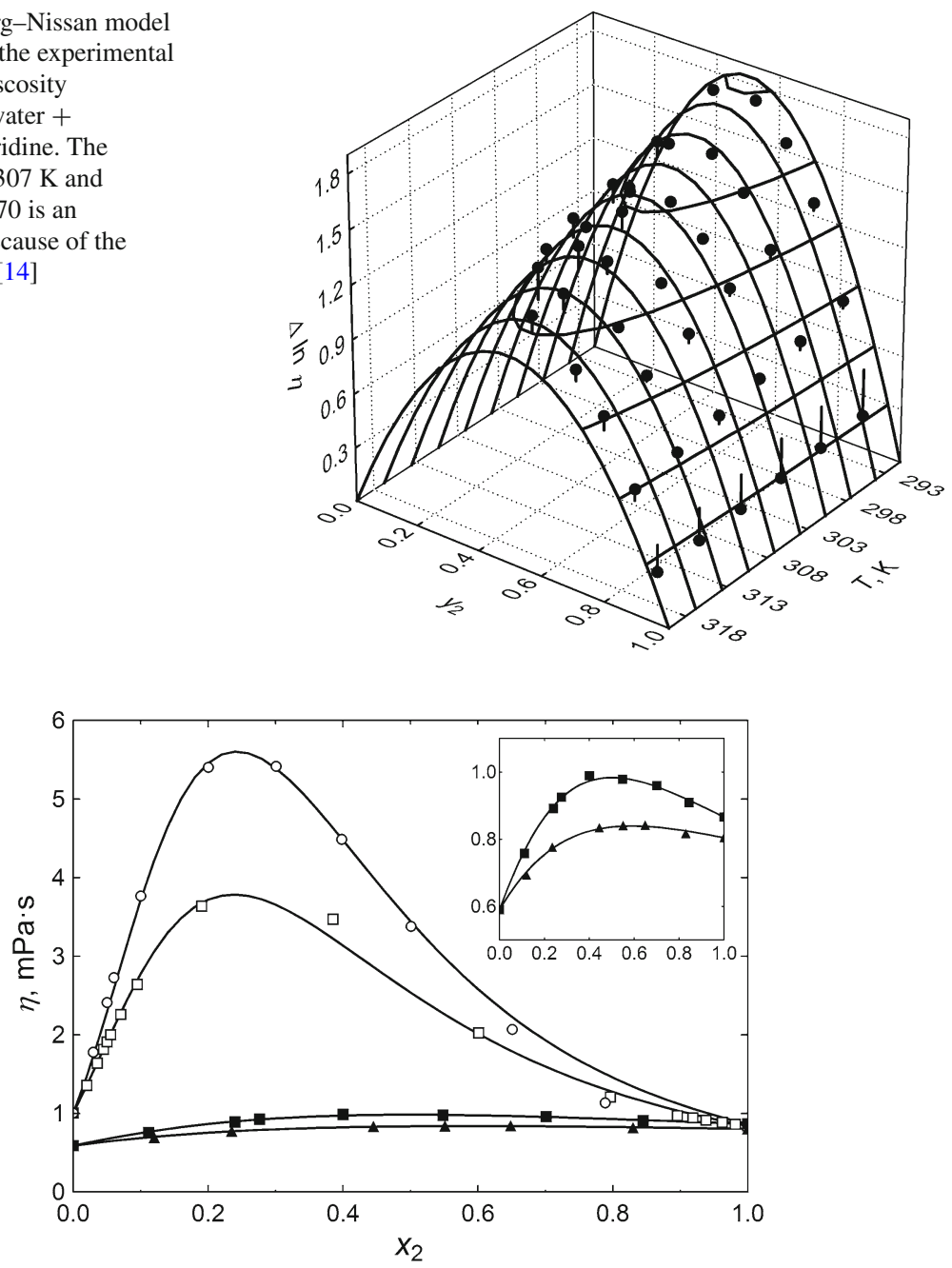

Fig. 3 Viscosity isotherms at $T=293.15 \mathrm{~K}$ for the following systems: methanol +2 -methylpyridine $(\boldsymbol{\Delta})$, methanol + 2,6-dimethylpyridine $(\square)$; water + 2-methylpyridine $(\square)$, and water + 2,6-dimethylpyridine ( $\bigcirc$ ). Points - experimental viscosities, i.e., measured values for water +2 -methylpyridine or those calculated from Eq. 2 for the three other systems; lines - the Grunberg-Nissan model (Eq. 6) 
Table 5 Coefficients of Eq. 7 for the excess activation energy of viscous flow for aqueous mixtures at $T=293.15 \mathrm{~K}$ and for the methanolic ones at $T=293.15 \mathrm{~K}$ to $318.15 \mathrm{~K}$, standard deviations of the fit, $\delta$, and correlation coefficients $r$

\begin{tabular}{lllll}
\hline System & $b\left(\mathrm{~kJ} \cdot \mathrm{mol}^{-1}\right)$ & $k$ & $\delta\left(\mathrm{kJ} \cdot \mathrm{mol}^{-1}\right)$ & $r$ \\
\hline Water + 2,6-dimethylpyridine & $210 \pm 38$ & $1.73 \pm 0.12$ & 0.9 & 0.9908 \\
Water + 2-methylpyridine & $69 \pm 5$ & 1 & 2.2 & 0.9261 \\
Methanol + 2,6-dimethylpyridine & $3.47 \pm 0.33$ & 1 & 0.17 & 0.8673 \\
Methanol + 2-methylpyridine & $1.78 \pm 0.03$ & 1 & 0.02 & 0.9899 \\
\hline
\end{tabular}

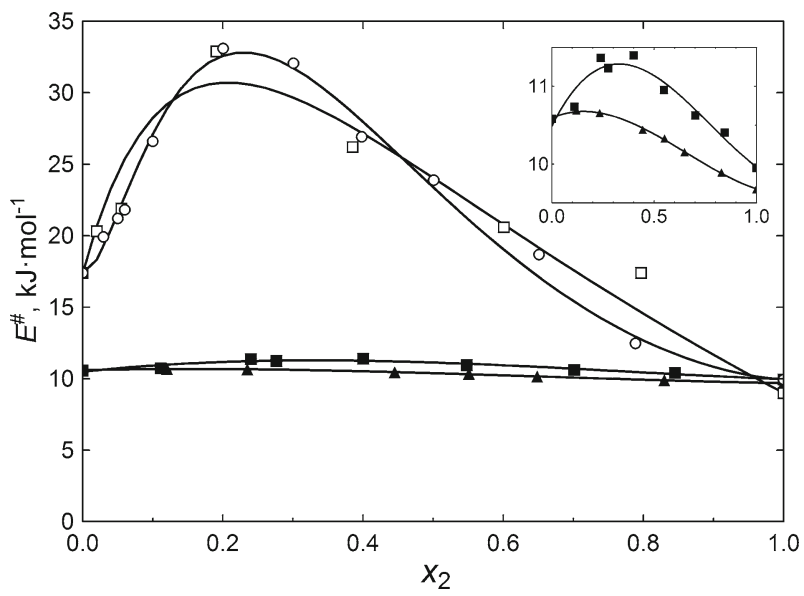

Fig. 4 Isotherms at $T=293.15 \mathrm{~K}$ of the activation energy of viscous flow for the following systems: methanol + 2-methylpyridine $(\boldsymbol{\Delta})$, methanol + 2,6-dimethylpyridine $(\boldsymbol{\square})$; water + 2-methylpyridine $(\square)$, and water $+2,6$-dimethylpyridine $(\bigcirc)$. Points-experimental energies; lines -interpolated Eq. 7

$$
E^{\#}=y_{1} E_{1}^{\#}+y_{2} E_{2}^{\#}+b\left(y_{1} y_{2}\right)^{k} .
$$

For the other three systems $k=1$. The regression coefficients, calculated by the least-squares method, are reported in Table 5. The $E^{\#}\left(x_{2}\right)$ functions are plotted in Fig. 4. The scatter of experimental points for 2-methylpyridine + water results most probably from the relatively low accuracy of the ultrasonic viscometer used in the previous study [19]. For methanolic systems, the functions are independent of temperature within the range of $293.15 \mathrm{~K}$ to $318.15 \mathrm{~K}$, since all activation energies are constant. The activation energy of viscous flow of water depends on temperature, which makes the $b$ coefficients for aqueous systems temperature-dependent as well.

\section{Discussion and Conclusions}

The high viscosity of aqueous solutions of 2-methylpyridine and 2,6-dimethylpyridine results most probably from the association of the hydrates due to hydrogen bonds between water molecules. The latter is also manifested, e.g., in the minima 


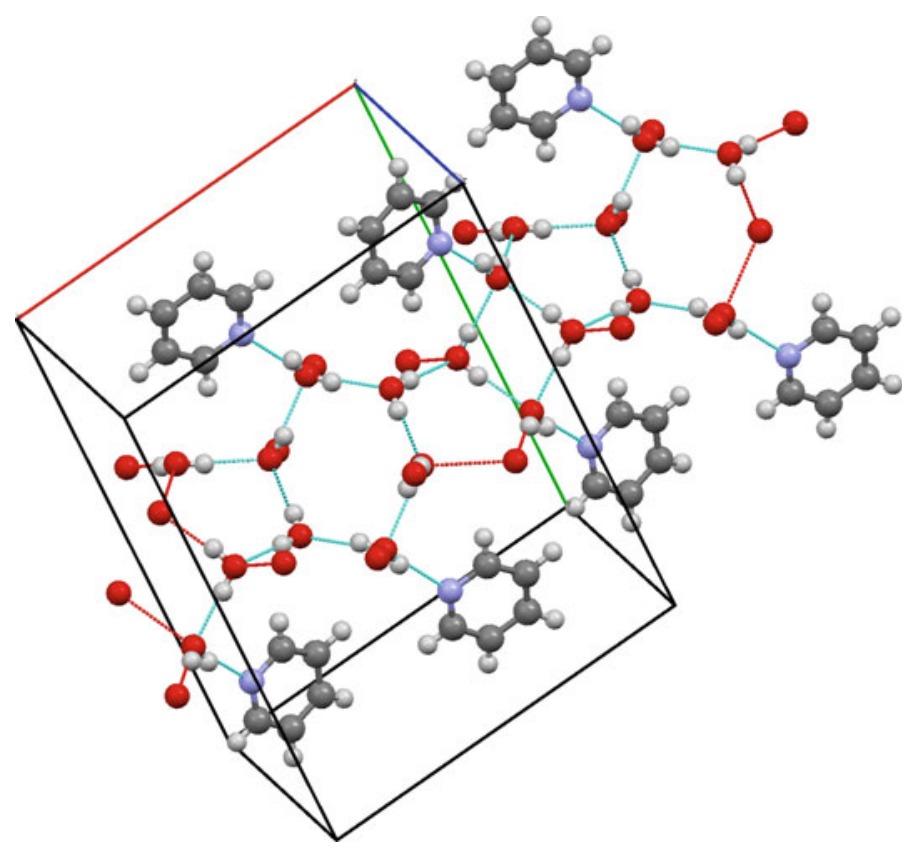

Fig. 5 Two-dimensional layers of water with the hydrogen-bonded pyridine molecules in the crystalline trihydrate. Picture generated using Mercury 2.3 program from the data reported in the Cambridge Structural Database [21]

of the compressibility isotherms $[18,20]$, in the ultrasound absorption maxima, and in the small-angle neutron scattering intensities dependent on the scattering vector [1]. The hydrogen bonds $\mathrm{O}-\mathrm{H} \cdots \mathrm{N}$ in methanolic mixtures, albeit of similar energy as those in aqueous ones, do not cause such spectacular effects. That points to the crucial role of water in the formation of large associates consisting of hydrates. As the molecular order in liquids may resemble that in the solid phase, some information can be gained from the crystallographic data. Although the structures of solid hydrates of 2-methylpyridine and 2,6-dimethylpyridine have not been described yet [21,22], the structures of pyridine and 4-methylpyridine trihydrates [23-25] may give an idea about the aggregation. In the trihydrates, hydrogen-bonded water molecules form twodimensional layers with protons protruding on either side, through which the amine molecules are connected (Fig. 5). Such an arrangement is impossible in methanolic systems; the methanol-amine complexes cannot associate because of the lack of proton-donating groups in the alcohol molecule.

The energy of $\mathrm{O}-\mathrm{H} \cdots \mathrm{N}$ bonds increases when methyl groups are substituted in the ortho position toward the nitrogen atom in the pyridine ring. The energies for 1:1 water-amine complexes, obtained from the second-order Møller-Plesset calculations, were $20.0 \mathrm{~kJ} \cdot \mathrm{mol}^{-1}$ for 2-methylpyridine and $21.2 \mathrm{~kJ} \cdot \mathrm{mol}^{-1}$ for 2,6-dimethylpyridine [26]. Owing to the co-operative nature of hydrogen bonds [27], the stronger is the $\mathrm{O}-\mathrm{H} \cdots \mathrm{N}$ bond, the stronger are the $\mathrm{O}-\mathrm{H} \cdots \mathrm{O}$ bonds in its vicinity. Consequently, the viscosities and activation energies of viscous flow of the 2,6-dimethylpyridine + 
water mixtures are higher than those of 2-methylpyridine ones. Similar regularity is evident for the methanolic systems.

The modified Grunberg-Nissan model with two adjustable parameters proved to be useful in the approximation of the binary mixture viscosity as a function of composition and temperature. Its main advantage is simplicity. Other models would probably require more fitting coefficients, similarly as, e.g., a Redlich-Kister correlation or McAllister's model suggested for the 2-methylpyridine-water system. The numbers of adjustable coefficients were four and three, respectively, for a single isotherm [28].

The fact that water forms larger clusters than methanol is reflected in the model coefficients: the mean degree of association $n=3$ for water and $n=2$ for methanol. Similarly, the interaction parameters $G_{12}^{0}$ for aqueous mixtures are a few times larger than those for the methanolic ones. Successful application of the Grunberg-Nissan approach to other associated mixtures seems possible, provided the concentrations would be defined for the mean kinetic entities rather than as analytical mole fractions. Probably a group contributions method could be worked out to estimate the interaction parameters. That would require, however, the same degree of association of the compared components in all the analyzed systems.

Open Access This article is distributed under the terms of the Creative Commons Attribution Noncommercial License which permits any noncommercial use, distribution, and reproduction in any medium, provided the original author(s) and source are credited.

\section{References}

1. W. Marczak, B. Czech, L. Almásy, D. Lairez, Phys. Chem. Chem. Phys. 13, 6260 (2011)

2. T. Kabeya, Y. Tamai, H. Tanaka, J. Phys. Chem. B 102, 899 (1998)

3. S.L. Boyd, R.J. Boyd, J. Chem. Theory Comput. 3, 54 (2007)

4. W. Marczak, K. Kiełek, B. Czech, H. Flakus, M. Rogalski, Phys. Chem. Chem. Phys. 11, 2668 (2009)

5. W. Marczak, A. Heintz, M. Bucek, J. Chem. Thermodyn. 36, 575 (2004)

6. J.S. Lomas, F. Maurel, J. Phys. Org. Chem. 21, 464 (2008)

7. B.E. Poling, J.M. Prausnitz, J.P. O'Connell, "Viscosity," in The Properties of Gases and Liquids, 5th edn. (McGraw-Hill, New York, 2001), chap. 9

8. D.R. Lide (ed.), CRC Handbook of Chemistry and Physics, 90th edn. (CRC Press, Boca Raton, FL, 2009)

9. A. Das, M. Frenkel, N.A.M. Gadalla, S. Kudchadker, K.N. Marsh, A.S. Rodgers, R.C. Wilhoit, J. Phys. Chem. Ref. Data 22, 659 (1993)

10. H. Freiser, W.L. Glowacki, J. Am. Chem. Soc. 70, 2575 (1948)

11. Y. Oshmyansky, H.J.M. Hanley, J.F. Ely, A.J. Kidnay, Int. J. Thermophys. 7, 599 (1986)

12. J. Wilke, H. Kryk, J. Hartmann, D. Wagner, Theory and Praxis of Capillary Viscometry-An Introduction (Schott-Geräte GmbH, Hofheim, Germany, 1994)

13. Poradnik Fizykochemiczny, Wydawnictwa Naukowo-Techniczne (Warszawa, Poland, 1974), pp. A188-A189

14. R.J.L. Andon, J.D. Cox, J. Chem. Soc. (London) 4601 (1952)

15. A. Stein, S.J. Davidson, J.C. Allegra, G.F. Allen, J. Chem. Phys. 56, 6164 (1972)

16. J.F. Swindells, R. Ullman, H. Mark, "Determination of Viscosity," in Technique of Organic Chemistry (Physical Methods of Organic Chemistry), vol. I, part 1, ed. by A. Weissberger (Interscience Publ., New York, 1959)

17. L. Sobczyk, "Gazy i ciecze," in Chemia fizyczna, 4th edn, ed. by A. Bielański, K. Gumiński, B. Kamieński, K. Pigoń, L. Sobczyk (PWN, Warszawa, 1980)

18. S. Ernst, W. Marczak, Bull. Pol. Acad. Sci. Chem. 43, 259 (1995) 
19. S. Ernst, W. Marczak, M. Waciński, Akustyka Molek. Kwant. 14, 113 (1993)

20. S. Ernst, W. Marczak, D. Kmiotek, J. Chem. Eng. Data 41, 128 (1996)

21. Cambridge Crystallographic Data Centre Database, CSD Version 5.32 (November 2010)

22. Crystallography Journals on Line, http://journals.iucr.org/, retrieved 16 March 2011

23. D. Mootz, H.-G. Wussow, Angew. Chem. Int. Edit. 19, 552 (1980)

24. D. Mootz, H.-G. Wussow, J. Chem. Phys. 75, 1517 (1981)

25. M. Born, D. Mootz, S. Schaefgen, Z. Naturforsch. B 50, 101 (1995)

26. I. Pápai, G. Jancsó, J. Phys. Chem. A 104, 2132 (2000)

27. G.A. Jeffrey, An Introduction to Hydrogen Bonding (Oxford University Press, New York, 1997)

28. M.-J. Lee, M.-C. Wei, J. Chem. Eng. Data 37, 209 (1992) 